Hendriks, M., Delnoij, D., Groenewegen, P.P. Het meten van vertrouwen in de zorgverzekeraar: psychometrische eigenschappen van een Nederlandse vragenlijst. TSG: Tijdschrift voor Gezondheidswetenschappen: 2007, 85(5), 280-286

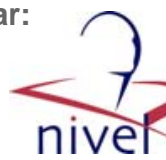

\begin{tabular}{|l|l|}
\hline $\begin{array}{l}\text { Postprint } \\
\text { Version }\end{array}$ & 1.0 \\
\hline Journal website & $\begin{array}{c}\text { http://vb23.bsl.nl/frontend/redir.asp?product=1388\%2D7491\&page=1388\%2D7 } \\
\text { 491/09014f3c801879fd\%2Ehtml\&highlight=meten+vertrouwen\&phrase= }\end{array}$ \\
\hline Pubmed link & \\
\hline DOI & \\
\hline
\end{tabular}

This is a NIVEL certified Post Print, more info at http://www.nivel.eu

\title{
Het meten van vertrouwen in de zorgverzekeraar: psychometrische eigenschappen van een Nederlandse vragenlijst
}

\author{
Michelle Hendriks, Diana M. J. Delnoij, Peter P. GroenewegeN* \\ * NIVEL, Nederlands instituut voor onderzoek van de gezondheidszorg
}

\begin{abstract}
Measuring trust in the health insurer: Psychometric testing of a Dutch questionnaire The aim of the present study was to develop a Dutch questionnaire to measure trust in health insurers. An American questionnaire was translated and filled in by Dutch respondents. Few respondents had problems filling in the questionnaire. Factor analyses revealed that insurer trust is a unidimensional construct with good internal consistency. As expected, trust in the health insurer was positively related with the general rating of the health insurer and the intention to stay insured with the same health insurer. It was also found that people who had no complaints or who were satisfied with the handling of their complaints trusted the insurer more than people who did have complaints or who were dissatisfied with the handling of their complaints. In conclusion, the Dutch questionnaire is a promising instrument to measure health insurer trust. Key words: trust, health insurer, psychometric testing, questionnaire development
\end{abstract}

Het doel van het onderzoek was om een Nederlandse vragenlijst te ontwikkelen die het vertrouwen van mensen in de zorgverzekeraar valide en betrouwbaar kan meten. Hiertoe werd een Amerikaanse vragenlijst vertaald en afgenomen bij een groep respondenten. Het bleek dat mensen weinig tot geen problemen ervoeren bij het invullen van de vragenlijst. Factoranalyses lieten zien dat het vertrouwen in de zorgverzekeraar een e'éndimensionaal construct is met een goede interne consistentie. Zoals verwacht hing het vertrouwen in de zorgverzekeraar positief samen met het algemene oordeel over de zorgverzekeraar en de intentie om verzekerd te blijven bij de zorgverzekeraar. Ook bleek dat mensen die geen klachten hadden of die tevreden waren over de klachtafhandeling meer vertrouwen hadden in de zorgverzekeraar dan mensen die wel klachten hadden of ontevreden waren over de klachtafhandeling. Het onderzoek laat zien dat de Nederlandse vragenlijst een veelbelovend instrument is om het vertrouwen in de zorgverzekeraar valide en betrouwbaar te meten. 
Hendriks, M., Delnoij, D., Groenewegen, P.P. Het meten van vertrouwen in de zorgverzekeraar: psychometrische eigenschappen van een Nederlandse vragenlijst. TSG: Tijdschrift voor Gezondheidswetenschappen: 2007, 85(5), 280-286

\section{INLEIDING}

Begin 2006 is in Nederland de nieuwe Zorgverzekeringswet ingevoerd. Ee'n van de doelen van deze wet is om door middel van marktwerking op de zorgverzekeringsmarkt een meer vraaggestuurde gezondheidszorg te bewerkstelligen. Een belangrijke indicator voor het optreden van deze marktwerking is het aantal mensen dat per jaar van zorgverzekeraar wisselt. Bij het wisselen van zorgverzekeraar speelt het vertrouwen dat mensen hebben in hun zorgverzekeraar en in zorgverzekeraars in het algemeen waarschijnlijk een rol. Er is echter tot op heden in Nederland geen meetinstrument beschikbaar om dit vertrouwen te meten. In dit artikel beschrijven we enkele psychometrische eigenschappen van een Nederlandse vragenlijst voor het meten van vertrouwen in de zorgverzekeraar. De Nederlandse overheid heeft de afgelopen jaren veel veranderingen doorgevoerd binnen de gezondheidszorg. Zo is begin 2006 de nieuwe Zorgverzekeringswet in werking getreden. Met deze wet is een uniforme basisverzekering ingevoerd en hebben verzekerden meer keuzevrijheid gekregen. De verzekerde kiest zelf bij welke zorgverzekeraar hij/zij de basisverzekering afsluit en zorgverzekeraars zijn voor de basisverzekering verplicht iedere verzekerde tegen dezelfde voorwaarden te accepteren. Verzekerden kunnen bovendien ieder jaar wisselen van zorgverzekeraar. Het idee is dat door de druk die uitgaat van deze mogelijkheid tot wisselen zorgverzekeraars elkaar gaan beconcurreren. Doordat consumenten gestimuleerd worden om de beste en/of goedkoopste zorgverzekeraar uit te kiezen, moet uiteindelijk een doelmatigere en meer vraaggestuurde gezondheidszorg tot stand komen. ${ }^{1}$ Een voorwaarde voor een goede werking van de zorgverzekeringsmarkt is dat verzekerden kunnen en willen wisselen van zorgverzekeraar. Voor de invoering van het nieuwe zorgstelsel wisselden maar weinig mensen van zorgverzekeraar. ${ }^{2 ; 3}$ Het aantal mensen dat van ziekenfonds veranderde, was de laatste jaren constant en laag (3\% tot $4 \%$ ). Met de invoering van het nieuwe zorgstelsel is echter veel aandacht besteed aan de mogelijkheid om over te stappen naar een andere zorgverzekeraar en veel mensen hebben van deze optie gebruik gemaakt. Een vijfde tot een kwart van de mensen is begin 2006 overgestapt naar een andere zorgverzekeraar. ${ }^{4 ; 5}$ Het is echter de vraag of de komende jaren opnieuw veel mensen besluiten om over te stappen. In 2007 is slechts $4 \%$ tot $6 \%$ van de verzekerden van polis of zorgvezekeraar veranderd. ${ }^{6 ; 7}$ Dit percentage is nauwelijks hoger dan het percentage overstappers in het oude ziekenfondssysteem. Een belangrijke vraag is waarom mensen van zorgverzekeraar wisselen. Waarschijnlijk zijn hierbij de ervaringen met de huidige zorgverzekeraar van belang. Meerdere onderzoeken laten zien dat mensen die tevreden zijn over hun zorgverzekeraar bij deze zorgverzekeraar verzekerd blijven. ${ }^{8,9}$ Uit een studie in Duitsland bleek echter dat mensen die van zorgverzekeraar waren gewisseld vaak niet ontevreden waren over hun vorige zorgverzekeraar. ${ }^{10}$ Blijkbaar zijn de ervaringen met de zorgverzekeraar alleen niet voldoende om het keuzegedrag van mensen te voorspellen. Het keuzegedrag op de zorgverzekeringsmarkt wordt mogelijk mede bepaald door het vertrouwen dat mensen hebben in hun zorgverzekeraar. ${ }^{2}$ Het verzekerd blijven bij dezelfde zorgverzekeraar kan beschouwd worden als loyaliteit van een persoon jegens de zorgverzekeraar. Uit onderzoek is gebleken dat het hebben van vertrouwen in een organisatie samengaat met een sterkere loyaliteit jegens de organisatie. ${ }^{11-13}$ Loyale klanten zijn geneigd om bij een bedrijf te blijven ondanks beperkte prijsstijgingen of een tijdelijke terugval in kwaliteit. ${ }^{14,15}$ Het hebben van vertrouwen kan gedefinieerd worden als 'de optimistische acceptatie van een kwetsbare situatie waarin de persoon er van uitgaat dat de andere partij opkomt voor zijn/haar belangen' ${ }^{16}$ Oftewel, indien iemand vertrouwen heeft in zijn/haar zorgverzekeraar, dan gaat de persoon er vanuit dat de zorgverzekeraar zijn/ haar belangen zal behartigen op momenten dat dit nodig is. Het is extra belangrijk om naast de ervaringen met de zorgverzekeraar ook het vertrouwen in de zorgverzekeraar te meten, omdat zorgverzekeringen voor een relatief lange tijd het karakter van een verwachting behouden. Er gaat vaak enige tijd voorbij tussen het afsluiten van de verzekering en het moment waarop iemand een beroep doet op de diensten van een zorgverzekeraar. ${ }^{17}$ In het begin kunnen mensen dus niet afgaan op hun eigen ervaringen, waardoor het vertrouwen in de 
Hendriks, M., Delnoij, D., Groenewegen, P.P. Het meten van vertrouwen in de zorgverzekeraar: psychometrische eigenschappen van een Nederlandse vragenlijst. TSG: Tijdschrift voor Gezondheidswetenschappen: 2007, 85(5), 280-286

zorgverzekeraar een grote rol speelt. Tot nu toe is er helaas weinig onderzoek gedaan naar het vertrouwen van mensen in hun zorgverzekeraar en in zorgverzekeraars in het algemeen. Een eerste stap is het ontwikkelen van een instrument om dit vertrouwen te meten. Hoewel er verschillende meetinstrumenten beschikbaar zijn voor het meten van de ervaringen met de zorgverzekeraar (denk bijvoorbeeld aan de Consumer Quality Index), wordt er in deze meetinstrumenten geen aandacht besteed aan het vertrouwen van mensen in de zorgverzekeraar. In de Verenigde Staten is door Zheng e.a. ${ }^{18}$ wel een dergelijk instrument ontwikkeld. Zij gaan er vanuit dat het vertrouwen in de zorgverzekeraar vier thema's kent: betrokkenheid, bekwaamheid, eerlijkheid en vertrouwelijkheid. Hun studie resulteerde in een vragenlijst van elf items. De items vormden samen e'én factor en de vragenlijst vertoonde een goede betrouwbaarheid en constructvaliditeit. Het vertrouwen in de zorgverzekeraar hing positief samen met de tevredenheid met de zorgverzekeraar, de wens om bij de zorgverzekeraar verzekerd te blijven, het hebben van voldoende keuze uit zorgverzekeraars, en het ontbreken van meningsverschillen met de zorgverzekeraar. ${ }^{18}$ Het doel van het huidige onderzoek was om een Nederlandse vragenlijst te ontwikkelen die het vertrouwen van mensen in de zorgverzekeraar valide en betrouwbaar kan meten. Hiertoe hebben we de vragenlijst van Zheng e.a. vertaald en afgenomen bij een groep respondenten. In dit artikel worden enkele psychometrische eigenschappen van de Nederlandse versie van de vragenlijst beschreven.

\section{METHODE}

\section{Vertaling van de vragenlijst}

De vragenlijst van Zheng e.a. ${ }^{18}$ over het vertrouwen in de zorgverzekeraar werd vertaald via de volgende procedure: ${ }^{19} 1$ Twee onafhankelijke vertalers vertaalden de vragenlijst van het Engels in het Nederlands; 2 De vertalers en de onderzoeker (MH) stelden een consensusversie van de vragenlijst in het Nederlands vast; 3 De Nederlandse consensusversie werd door twee andere onafhankelijke vertalers terugvertaald van het Nederlands in het Engels; 4 De terugvertalers en de onderzoeker bespraken de verschillen tussen de twee terugvertalingen en de originele Amerikaanse versie van de vragenlijst. De Nederlandse versie werd op enkele punten bijgesteld. Tabel 1 geeft zowel de originele Amerikaanse versie als de Nederlandse vertaalde versie van de vragenlijst. Respondenten geven per stelling aan in hoeverre ze het met de stelling eens zijn met behulp van de volgende vijf antwoordcategoriee "n: geheel mee eens, mee eens, neutraal, mee oneens, geheel mee oneens.

\section{[TABEL 1]}

\section{Gegevensverzameling}

De Nederlandse versie van de vertrouwen-vragenlijst is opgestuurd naar 1.500 leden van het VGZ Verzekerdenpanel. Het VGZ Verzekerdenpanel is een panel bestaande uit ruim 11.000 mensen die bij VGZ verzekerd zijn. ${ }^{20}$ De respondenten vulden twee versies van de vertrouwen- vragenlijst in, een versie over het vertrouwen in zorgverzekeraars in het algemeen en een versie over het vertrouwen in VGZ in het bijzonder. De vertrouwenvragenlijst maakte onderdeel uit van een uitgebreidere vragenlijst met daarin ook vragen over: Het algemeen oordeel over VGZ: e'én item varie“rend van 0 (slechts mogelijke zorgverzekeraar) tot en met 10 (best mogelijke zorgverzekeraar). Dit item is afgeleid van de CQ Index Zorg en Zorgverzekering; ${ }^{21}$ Intentie om verzekerd te blijven bij VGZ: vijf items over de intentie om verzekerd te blijven bij VGZ (Cronbachs alfa is 0,85 en de somscore kan varie"ren van 5 tot en met 25); Klachtafhandeling door VGZ: de respondenten gaven aan of ze in de afgelopen 12 maanden VGZ hadden benaderd met een klacht of probleem (nee/ja). De personen die een klacht of probleem ingediend hadden, gaven vervolgens aan of ze 
Hendriks, M., Delnoij, D., Groenewegen, P.P. Het meten van vertrouwen in de zorgverzekeraar: psychometrische eigenschappen van een Nederlandse vragenlijst. TSG: Tijdschrift voor Gezondheidswetenschappen: 2007, 85(5), 280-286

tevreden waren over hoe VGZ was omgegaan met de klacht of probleem (nee/ja) en of ze tevreden waren over het eindresultaat van de klachtafhandeling (nee/ja).

\section{Statistische analyses}

Ten eerste werd bekeken hoe de respondenten de items hadden ingevuld. Hierbij hanteerden we de volgende vuistregels. Het aantal mensen dat een item niet invulde mocht niet hoger zijn dan 5\% en de antwoorden mochten niet extreem scheef verdeeld zijn. Indien meer dan $80 \%$ van de respondenten hetzelfde antwoord kiest op een item, dan zijn de antwoorden zo weinig gevarieerd dat een vraag niet meer kan discrimineren tussen groepen respondenten. Om na te gaan of er e'én achterliggend construct (in dit geval vertrouwen in de zorgverzekeraar) ten grondslag lag aan alle items van de vragenlijst, voerden we een factoranalyse uit. Eerst controleerden we of de gegevens geschikt waren voor het uitvoeren van een factoranalyse. Zo is het belangrijk dat de antwoordpatronen op twee items niet teveel overlappen. Ieder item moet namelijk idealiter een unieke bijdrage leveren aan het achterliggende construct. Daarom bekeken we of de correlaties tussen twee items (inter-item correlaties) niet te hoog waren. Als grenswaarde hanteerden we een maximale inter-item correlatie van 0,7 ; de overlap in de antwoordpatronen is dan circa $50 \%$. Ook is gekeken naar de Kaiser-Meyer-Olkin ofwel KMO-waarde. De KMO-waarde geeft de 'factoranalyseerbaarheid' aan. Bij lage KMO-waarden (kleiner dan 0,5) moet factoranalyse niet toegepast worden, omdat de variabelen dan weinig tot niets gemeenschappelijk hebben. De correlaties tussen de items kunnen in dat geval niet verklaard worden door een achterliggend construct. Bij hoge waarden (groter dan 0,7) kan factoranalyse zonder bezwaar toegepast worden. Voor de factoranalyse werden de respondenten opgedeeld in twee willekeurige groepen. Op de antwoorden van 75\% van de respondenten (Groep 1) werd een explorerende factoranalyse (principale componentenanalyse) uitgevoerd. Daarna bekeken we met behulp van een bevestigende factoranalyse (principale componentenana- lyse) of dezelfde factorstructuur ook te vinden was in de antwoorden van de overige $25 \%$ van de respondenten (Groep 2). Een volgende stap is om te bekijken of de gevonden factoren voldoende betrouwbaar zijn. Een maat hiervoor is Cronbachs alfa. Cronbachs alfa geeft aan in hoeverre de items hetzelfde concept meten door te berekenen of de antwoorden van de respondenten op de verschillende items consistent zijn. Een alfa van 0,7 of hoger duidt op een goede interne consistentie. Ook bekeken we of bepaalde items beter verwijderd konden worden, omdat ze een lage correlatie hadden met de factor (item-to-total correlatie) en/of omdat Cronbachs alfa toenam bij verwijdering van het item. We bekeken de constructvaliditeit van de vragenlijst door de scores op de vragenlijst te vergelijken met de scores uit de Verenigde Staten verkregen door Zheng e.a. ${ }^{18}$ Met behulp van Pearsoncorrelaties werd het vertrouwen in VGZ gerelateerd aan de het algemene oordeel over VGZ en aan de intentie om verzekerd te blijven bij VGZ. Daarnaast bekeken we met behulp van ANOVAs of het indienen van een klacht en de tevredenheid over de klachtafhandeling samenhingen met het vertrouwen in VGZ.

\section{RESULTATEN}

\section{Respondenten}

Van de 1.500 panelleden hebben $1.471(98,1 \%)$ mensen de vragenlijst ingevuld teruggestuurd. Van alle respondenten was $55,4 \%(n=815)$ man en $43,8 \%(n=645)$ vrouw. Van $10(0,7 \%)$ personen was het geslacht onbekend. De leeftijd varieerde van 19 tot en met 95 jaar en de gemiddelde leeftijd was 61,6 jaar $(\mathrm{SD}=13,6)$.

\section{Verdeling van de antwoorden}

De verdeling van de antwoorden is weergegeven in tabel 2 . Alle items werden door het overgrote deel van de respondenten ingevuld. Geen e'én item was door meer dan 5\% van de respondenten niet ingevuld. De antwoordcategoriee"n neutraal, mee eens (voor positief geformuleerde items) en mee oneens (voor negatief geformuleerde items) werden het meest 
Hendriks, M., Delnoij, D., Groenewegen, P.P. Het meten van vertrouwen in de zorgverzekeraar: psychometrische eigenschappen van een Nederlandse vragenlijst. TSG: Tijdschrift voor Gezondheidswetenschappen: 2007, 85(5), 280-286

ingevuld door de respondenten (zie tabel 2). Voor geen e'én item gold dat $80 \%$ of meer van de respondenten hetzelfde antwoord gaf. Item 10 (U denkt dat wanneer u een vraag hebt, zorgverzekeraars/VGZ u een eerlijk antwoord zal geven) blijkt van alle items het minst discriminerend vermogen te hebben.

\section{[TABEL 2]}

\section{Factoranalyses}

De inter-item correlaties waren niet te hoog ( 0,7 of hoger) voor het uitvoeren van factoranalyses. De hoogste correlaties werden gevonden tussen de items ' $U$ denkt dat wanneer u een vraag hebt, zorgverzekeraars/VGZ u een eerlijk antwoord zal geven' en 'Al met al vertrouwt u zorgverzekeraars/VGZ volkomen'. Deze correlatie was 0,61 voor de items over zorgverzekeraars in het algemeen en 0,60 voor de items over VGZ. De KMOwaarde was zowel bij de items over de zorgverzekeraars $(\mathrm{KMO}=0,89)$ als bij de items over VGZ $(\mathrm{KMO}=0,90)$ voldoende hoog (hoger dan 0,7). Deze resultaten laten zien dat de gegevens geschikt zijn voor het uitvoeren van een factoranalyse. Bij de exploratieve factoranalyses op de antwoorden van Groep 1 (75\% van de respondenten) kwamen twee factoren naar voren met een eigenwaarde groter dan 1 . Ook de scree plots duidden op de aanwezigheid van twee factoren. Factor 1 verklaarde respectievelijk 32,4\% (zorgverzekeraars) en 37,3\% (VGZ) van de variantie en Factor 2 verklaarde respectievelijk $5,8 \%$ (zorgverzeke- raars) en 6,5\% (VGZ) van de variantie. De factorladingen waren voor alle items hoger op Factor 1 dan op Factor 2. Bij de bevestigende factoranalyses op de antwoorden van Groep 2 (25\% van de respondenten) werd het aantal factoren op e'én vastgesteld. Deze factor verklaarde respectievelijk 34,0\% (zorgverzekeraars) en 34,3\% (VGZ) van de variantie in de antwoorden. In tabel 3 worden de factorladingen van de afzonderlijk items op Factor 1 weergegeven. Alle factorladingen zijn absoluut gezien hoger dan 0,4, wat erop duidt dat alle items voldoende samenhang vertonen met de achterliggende factor. Item 11 (Al met al vertrouwt u zorgverzekeraars/ VGZ volkomen) heeft de hoogste absolute lading. Daarnaast geldt dat negatief geformuleerde items een positieve lading hebben en dat positief geformuleerde items een negatieve lading hebben. Factor 1 kan gei"nterpreteerd worden als een maat voor het (wan)vertrouwen van een persoon in zorgverzekeraars in het algemeen of VGZ in het bijzonder. Hoe hoger de score op de factor, hoe lager het vertrouwen in de zorgverzekeraars of VGZ is.

\section{[TABEL 3]}

\section{Interne consistentie}

De interne consistentie van de vragenlijst was hoog. Cronbachs alfa was 0,85 voor de items over de zorgverzekeraars en 0,83 voor de items over VGZ. Geen enkel item liet een lage item-to-total correlatie zien. Alle correlaties waren groter dan 0,39 voor de items over de zorgverzekeraars en groter dan 0,38 voor de items over VGZ. Bovendien verbeterde Cronbachs alfa niet na verwijdering van een bepaald item

\section{Constructvaliditeit}

In navolging van Zheng e.a. werd het vertrouwen in de zorgverzekeraar gemeten als de somscore over de elf items na hercodering van de negatief geformuleerde items. ${ }^{18} \mathrm{De}$ somscore kan varie"ren van 11 tot 55 en een hogere score betekent meer vertrouwen. Voor de items over zorgverzekeraars in het algemeen varieerde de somscore van 15 tot en met 55 met een gemiddelde van 36,6 ( $\mathrm{SD}=5,8$ ). De somscore van het vertrouwen in VGZ varieerde van 16 tot en met 55 met een gemiddelde van 39,0 (SD = 5,7). Het vertrouwen van de Nederlandse respondenten in hun zorgverzekeraar is vergelijkbaar met het vertrouwen van Amerikaanse respondenten. In de studie van Zheng e.a. varieerde de somscore van 11 tot 55 met een gemiddelde van 36,5 ( $\mathrm{SD}=7,8$ ) in een nationale steekproef en van 12 tot 55 met een 
Hendriks, M., Delnoij, D., Groenewegen, P.P. Het meten van vertrouwen in de zorgverzekeraar: psychometrische eigenschappen van een Nederlandse vragenlijst. TSG: Tijdschrift voor Gezondheidswetenschappen: 2007, 85(5), 280-286

gemiddelde van 37,0 $(\mathrm{SD}=7,0)$ in een regionale steekproef. ${ }^{18}$ Tabel 4 laat zien dat een groter vertrouwen in VGZ samenging met een hoger algemeen oordeel over VGZ en een grotere intentie om verzekerd te blijven bij VGZ. Het algemeen oordeel over VGZ was ook positief gerelateerd aan de intentie om verzekerd te blijven bij VGZ. Daarnaast rapporteerden de personen die een klacht hadden ingediend in de afgelopen 12 maanden $(\mathrm{M}=37,7, \mathrm{SD}=5,8)$ een lager vertrouwen in VGZ dan de personen die dit niet hadden gedaan $(\mathrm{M}=39,9, \mathrm{SD}=$ 5,5; $\mathrm{F}=51,56, \mathrm{p}<0,001)$. Van de mensen die een klacht hadden ingediend $(\mathrm{n}=542)$, rapporteerden de personen die tevreden waren over de manier van omgaan met de klacht (M $=39,4, \mathrm{SD}=5,1)$ en over het eindresultaat van de klachtafhandeling $(\mathrm{M}=38,6, \mathrm{SD}=5,6)$ een hoger vertrouwen in VGZ dan de personen die niet tevreden waren over de manier van omgaan $(M=35,6, S D=6,0 ; F=59,60, p<0,001)$ of het eindresultaat $(M=35,7, S D=6,1$; $\mathrm{F}=20,88, \mathrm{p}<0,001)$.

\section{[Tabel 4]}

\section{DISCUSSIE}

Begin 2006 is in Nederland de nieuwe Zorgverzekeringswet ingevoerd om zo ondermeer marktwerking binnen de gezondheidszorg te introduceren. Een voorwaarde voor het optreden van deze marktwerking is dat verzekerden kunnen en willen wisselen van zorgverzekeraars. Belangrijk bij het wisselen van zorgverzekeraars is het vertrouwen dat mensen hebben in de zorgverzekeraar. Tot op heden is er in Nederland echter geen meetinstrument beschikbaar om dit vertrouwen te meten. Met het huidige onderzoek werd beoogd om een Nederlandse vragenlijst te ontwikkelen die het vertrouwen van mensen in de zorgverzekeraar betrouwbaar en valide kan meten. Daartoe hebben we een Amerikaanse vragenlijst over het vertrouwen in zorgverzekeraars vertaald en enkele psychometrische eigenschappen van de Nederlandse versie bepaald. De resultaten lieten zien dat mensen weinig tot geen problemen ervoeren bij het invullen van de vragenlijst. Net als in de studie van Zheng e.a. ${ }^{18}$ vormden de elf items van de vragenlijst e'én factor met een goede interne con- sistentie. Dit duidt erop dat de items e'én achterliggend construct meten. Aangezien het item 'Al met al vertrouwt u zorgverzekeraars/VGZ volkomen' de hoogste factorlading en hoogste correlatie met de schaal had, kan geconcludeerd worden dat de vragenlijst zoals beoogd het vertrouwen in de zorgverzekeraar meet. Hoewel de vier thema's van vertrouwen (betrokkenheid, bekwaamheid, eerlijkheid en vertrouwelijkheid ${ }^{18}$ ) allemaal in de vragenlijst vertegenwoordigd zijn, lijken verzekerden hiertussen geen onderscheid te maken. Het kan echter goed zijn dat elf items te weinig is om de vier factoren te kunnen meten. Iedere factor kan dan maximaal met slechts drie items bevraagd worden. De resultaten lijken erop te wijzen dat de vragenlijst sterk ingekort kan worden. In de Verenigde Staten is reeds een verkorte versie van vijf items ontwikkeld en deze versie liet een goede interne consistentie en constructvaliditeit zien. ${ }^{22}$ Mogelijk is zelfs alleen het item 'Al met al vertrouwt u uw zorgverzekeraar volkomen' voldoende om het vertrouwen van mensen in zorgverzekeraars te meten. Toekomstig onderzoek moet uitwijzen of ook een Nederlandse verkorte versie goede psychometrische eigenschappen heeft. De verwachte relaties tussen het vertrouwen in de zorgverzekeraar enerzijds en het algemeen oordeel over de zorgverzekeraar en het toekomstig keuzegedrag anderzijds werden bevestigd. Mensen die meer vertrouwen hadden in hun zorgverzekeraar gaven een hoger oordeel aan hun zorgverzekeraar en hadden minder de intentie om van zorgverzekeraar te veranderen. Ook hadden mensen met klachten over of problemen met de zorgverzekeraar zoals verwacht minder vertrouwen in de zorgverzekeraar dan mensen zonder klachten of problemen in het afgelopen jaar. De mensen die vervolgens tevreden waren over de klachtafhandeling hadden meer vertrouwen in de zorgverzekeraar dan de mensen die niet tevreden waren. In de huidige studie is een eerste stap gezet voor de ontwikkeling van een Nederlandse vragenlijst om het vertrouwen van mensen in zorgverzekeraars te kunnen meten. De betrouwbaarheid en validiteit van de vragenlijst moeten echter nog nader onderzocht worden. Zo is nog niet gekeken naar de test-hertest 
Hendriks, M., Delnoij, D., Groenewegen, P.P. Het meten van vertrouwen in de zorgverzekeraar: psychometrische eigenschappen van een Nederlandse vragenlijst. TSG: Tijdschrift voor Gezondheidswetenschappen: 2007, 85(5), 280-286

betrouwbaarheid. Ook is enkel de relatie tussen het vertrouwen en andere subjectieve maten onderzocht. In toekomstig onderzoek zou gekeken moeten worden naar de relatie tussen het vertrouwen in de zorgverzekeraar, zoals gemeten met de vragenlijst, en het daadwerkelijke keuzegedrag op de zorgverzekeringsmarkt. Een interessante vraag is wat het toekomstige keuzegedrag het beste voorspelt: is dit het vertrouwen in de zorgverzekeraar of de ervaringen met de zorgverzekeraar? Tevredenheid is gebaseerd op daadwerkelijke ervaringen met de zorgverzekeraar in het verleden. ${ }^{16}$ Het hebben van vertrouwen zegt meer over de verwachtingen in de toekomst. Indien iemand vertrouwen heeft in zijn/haar zorgverzekeraar, dan hoeven slechte ervaringen niet noodzakelijk te leiden tot het wisselen van zorgverzekeraar. In plaats daarvan kan de persoon de slechte service door de vingers zien en bij de zorgverzekeraar blijven erop vertrouwende dat de service in de toekomst beter zal zijn. Uit een studie van Thom e.a. ${ }^{23}$ bleek dat het vertrouwen in de huisarts beter voorspelde welke patie"nten bij hun arts bleven en de behandelrichtlijnen opvolgden dan de tevredenheid met de huisarts. Met het VGZ Verzekerdenpanel hebben wij de mogelijkheid om personen in de tijd te volgen en zo te bepalen wat de relatieve invloed is van de tevredenheid met en het vertrouwen in de zorgverzekeraar op het daadwerkelijke keuzegedrag. Een ander belangrijk punt is of met de vragenlijst veranderingen in het vertrouwen over de tijd gemeten kunnen worden. Indien dit het geval is, dan kan de vragenlijst gebruikt worden om het vertrouwen van Nederlandse consumenten in zorgverzekeraars in het algemeen te monitoren. De invloed van beleidsveranderingen, zoals de invoering van de nieuwe Zorgverzekeringswet in Nederland, op het publiek vertrouwen in zorgverzekeraars kan zo worden onderzocht. Zorgverzekeraars zelf kunnen de vragenlijst gebruiken om de effecten van hun eigen beleidsstrategiee"n op het vertrouwen in de organisatie na te gaan.

\section{CONCLUSIE}

De huidige studie laat zien dat de Nederlandse vragenlijst een veelbelovend instrument is om het vertrouwen in de zorgverzekeraar valide en betrouwbaar te meten. De vragenlijst heeft een goede interne consistentie en vertoont de verwachte relaties met relevante constructen zoals het algemeen oordeel over de zorgverzekeraar en de intentie verzekerd te blijven bij de zorgverzekeraar. Toekomstig onderzoek moet uitwijzen of het vertrouwen in de zorgverzekeraar, zoals gemeten met de vragenlijst, een goede voorspeller is van het daadwerkelijke keuzegedrag van mensen op de zorgverzekeringsmarkt.

\section{LITERATUUR}

1. Ministerie van VWS. Vraag aan bod. Den Haag: Ministerie van VWS, 2000.

2. Kerssens J, Delnoij D, Verweij J, Schee E van der. De keuze van ziekenfondsverzekerden voor een zorgverzekeraar. Tijdschr Gezondheidswet 2002; 80:35-42.

3. Schee $E$ van der, Friele R, Delnoij D. Weinig mensen veranderen van ziekenfonds. Utrecht: NIVEL, 2005.

4. Jong JD de, Delnoij D, Groenewegen P. Verzekerdenmobiliteit is hoog. Ook ouderen zijn overgestapt. Utrecht: NIVEL, 2006.

5. TNS NIPO/ RTL Nieuws. Kwart Nederlands inmiddels geswitcht. Amsterdam: TNS NIPO/ RTL Nieuws, 2006.

6. Jong J de, Groenewegen P. Percentage overstappers van zorgverzekeraar valt terug. Collectivisering zet door. Utrecht: NIVEL, 2007.

7. Smit M, Mokveld P. Verzekerdenmobiliteit en keuzegedrag. Hoe staat het ervoor in 2007? Zeist: Vektis, 2007.

8. Gamble JE, Icenogle ML, Bryan NB, Rickert DA. The effects of open access on member satisfaction and intentions to remain in an HMO. Health Care Management Rev 2000; 25:34-47.

9. Kerssens JJ, Groenewegen PP. Consumer choice of social health insurance in managed competition. Health Expect 2003; 6:312- 322. 
Hendriks, M., Delnoij, D., Groenewegen, P.P. Het meten van vertrouwen in de zorgverzekeraar: psychometrische eigenschappen van een Nederlandse vragenlijst. TSG: Tijdschrift voor Gezondheidswetenschappen: 2007, 85(5), 280-286

10. Gress S, Groenewegen PP, Kerssens JJ, Braun B, Wasem J. Free choice of sickness funds in regulated competition: evidence from Germany and the Netherlands. Health Policy 2002; 60: 235-254.

11. Harris LC, Goode MMH. The four levels of loyalty and the pivotal role of trust: a study of online service dynamics. J Retail 2004; 80:139-58.

12. Singh J, Sirdeshmukh D. Agency and trust mechanisms in consumer satisfaction and loyalty judgments. J Acad Market Sci 2000; 28:150-68.

13. Sirdeshmukh D, Singh J, Sabol B. Consumer trust, value, and loyalty in relational exchanges. J Market 2002; 66:15-37.

14. Chaudhuri A, Holbrook MB. The chain of effects from brand trust and brand affect to brand performance: the role of brand loyalty. J Market 2001;65:81-93.

15. Dick AS, Basu K. Customer loyalty: toward an integrated conceptual framework. J Acad Market Sci 1994; 22:99-113.

16. Hall MA, Dugan E, Zheng B, Mishra AK. Trust in physicians and medical institutions: What is it, can it be measured, and does it matter? Milbank Quart 2001; 79:613-39.

17. Horstman K, Made J van de. Exit en voice in de verzekeringswereld. Gebrekkige gezondheid, gebrekkig verweer? B en M: Tijdschr Beleid, Politiek Maatschj 2004; 31:42-51.

18. Zheng B, Hall MA, Dugan E, Kidd KE, Levine D. Development of a scale to measure patients' trust in health insurers. Health Serv Res 2002; 37:185-200.

19. Bullinger M. German translation and psychometric testing of the SF-36 Health Survey: preliminary results from the IQOLA project. Soc Sci Med 1995;41:1359-66.

20. Hendriks M, Delnoij DMJ, Groenewegen PP. Het VGZ Verzekerdenpanel. Achtergronddocument en basisgegevens 2006. Utrecht: NIVEL, 2006.

21. Damman OC, Hendriks M, Delnoij DMJ, Spreeuwenberg P. Ervaringen van verzekerden met de zorg en de zorgverzekeraar. Meting 2006 voor www.kiesBeter.nl. Utrecht: NIVEL, 2006.

22. Dugan E, Trachtenberg F, Hall MA. Development of abbreviated measures to assess patient trust in a physician, a health insurer, and the medical profession. Health Serv Res 2005;40:5.

23. Thom DH, Ribisl KM, Stewart AL, Luke DA. Stanford Trust Study Physicians. Further validation and reliability testing of the trust in physician scale. Med Care 1999;37:510-7.

\section{TABELLEN}

Tabel 1 Vertaling van de Amerikaanse vragenlijst

\begin{tabular}{|c|c|c|}
\hline Item & Amerikaanse versie & Nederlandse versie \\
\hline 1 & $\begin{array}{l}\text { You think the people at XXX are } \\
\text { completely honest. }\end{array}$ & $\begin{array}{l}\text { U denkt dat de medewerkers van XXX } \\
\text { volkomen eerlijk zijn. }\end{array}$ \\
\hline 2 & $\begin{array}{l}\text { XXX cares more about saving } \\
\text { money than about getting you the } \\
\text { treatment you need. }\end{array}$ & $\begin{array}{l}\text { XXX vindt geld besparen belangrijker } \\
\text { dan de benodigde zorg voor } \mathrm{u} \text { in te } \\
\text { kopen. }\end{array}$ \\
\hline 3 & $\begin{array}{l}\text { As far as you know, the people at } \\
\text { XXX are very good at what they do. }\end{array}$ & $\begin{array}{l}\text { Voor zover u weet, zijn medewerkers } \\
\text { van XXX erg goed in hun werk. }\end{array}$ \\
\hline 4 & $\begin{array}{l}\text { If someone at XXX made a serious } \\
\text { mistake, you think they would try } \\
\text { to hide it. }\end{array}$ & $\begin{array}{l}\text { U denkt dat wanneer een medewerker } \\
\text { van XXX een ernstige fout zou maken } \\
\text { hij/zij dat zou proberen te verbergen. }\end{array}$ \\
\hline 5 & $\begin{array}{l}\text { You feel like you have to double } \\
\text { check everything XXX does. }\end{array}$ & $\begin{array}{l}U \text { hebt het gevoel dat } u \text { alles wat XXX } \\
\text { doet extra moet controleren. }\end{array}$ \\
\hline 6 & $\begin{array}{l}\text { You worry that private information } \\
\text { XXX has about you could be used } \\
\text { against you. }\end{array}$ & $\begin{array}{l}\text { U bent bang dat persoonlijke gegevens } \\
\text { die XXX van } u \text { heeft, tegen u gebruikt } \\
\text { zouden kunnen worden. }\end{array}$ \\
\hline 7 & $\begin{array}{l}\text { You worry there are a lot of } \\
\text { loopholes in what XXX covers that } \\
\text { you don't know about. }\end{array}$ & $\begin{array}{l}U \text { bent bang dat er veel gaten zitten in } \\
\text { de dekking van XXX waar u niets van } \\
\text { af weet. }\end{array}$ \\
\hline 8 & $\begin{array}{l}\text { You believe XXX will pay for } \\
\text { everything it is supposed to, even } \\
\text { really expensive treatments. }\end{array}$ & $\begin{array}{l}\text { U denkt dat XXX voor alles zal betalen } \\
\text { waarvoor ze hoort te betalen, zelfs voor } \\
\text { zeer dure behandelingen. }\end{array}$ \\
\hline 9 & $\begin{array}{l}\text { If you got really sick, you are afraid } \\
\text { XXX might try to stop covering } \\
\text { you altogether. }\end{array}$ & $\begin{array}{l}\text { U bent bang dat als u erg ziek zou } \\
\text { worden, XXX zou proberen uw } \\
\text { dekking volledig stop te zetten. }\end{array}$ \\
\hline 10 & $\begin{array}{l}\text { If you have a question, you think } \\
\text { XXX will give a straight answer. }\end{array}$ & $\begin{array}{l}\text { U denkt dat wanneer u een vraag hebt, } \\
\text { XXX u een eerlijk antwoord zal geven. }\end{array}$ \\
\hline 11 & $\begin{array}{l}\text { All in all, you have complete trust } \\
\text { in XXX. }\end{array}$ & Al met al vertrouwt u XXX volkomen. \\
\hline
\end{tabular}


Hendriks, M., Delnoij, D., Groenewegen, P.P. Het meten van vertrouwen in de zorgverzekeraar: psychometrische eigenschappen van een Nederlandse vragenlijst. TSG: Tijdschrift voor

Tabel 2 Percentage respondenten dat een bepaald antwoord gaf

\begin{tabular}{|c|c|c|c|c|c|c|}
\hline & $\begin{array}{c}\text { Geheel } \\
\text { mee eens }\end{array}$ & Mee eens & Neutraal & $\begin{array}{c}\text { Mee } \\
\text { oneens }\end{array}$ & $\begin{array}{c}\text { Geheel } \\
\text { mee oneens }\end{array}$ & $\begin{array}{c}\text { Niet } \\
\text { ingevuld }\end{array}$ \\
\hline \multicolumn{7}{|c|}{ Zorgverzekeraars in het algemeen } \\
\hline item 1 & 8,8 & 35,2 & 44,3 & 9,2 & 0,8 & 1,6 \\
\hline item 2 & 5,0 & 22,8 & 44,6 & 21,3 & 3,8 & 2,5 \\
\hline item 3 & 3,9 & 35,2 & 50,7 & 8,8 & 0,3 & 1,1 \\
\hline item 4 & 1,5 & 17,3 & 50,6 & 25,6 & 2,9 & 2,0 \\
\hline item 5 & 4,8 & 30,7 & 27,8 & 31,8 & 3,2 & 1,8 \\
\hline item 6 & 1,4 & 9,4 & 27,3 & 48,9 & 11,2 & 1,8 \\
\hline item 7 & 3,4 & 20,7 & 39,3 & 30,6 & 4,6 & 1,5 \\
\hline item 8 & 7,1 & 35,5 & 26,2 & 24,7 & 5,0 & 1,5 \\
\hline item 9 & 1,7 & 5,9 & 21,5 & 53,6 & 15,8 & 1,4 \\
\hline item 10 & 11,1 & 56,5 & 25,4 & 5,0 & 0,7 & 1,3 \\
\hline item 11 & 9,8 & 35,8 & 41,1 & 11,0 & 1,2 & 1,2 \\
\hline \multicolumn{7}{|c|}{ VGZ } \\
\hline item 1 & 9,7 & 47,0 & 37,4 & 4,5 & 0,3 & 1,0 \\
\hline item 2 & 1,9 & 13,3 & 39,6 & 37,8 & 6,0 & 1,4 \\
\hline item 3 & 5,2 & 45,2 & 40,7 & 7,0 & 0,4 & 1,5 \\
\hline item 4 & 1,0 & 12,2 & 47,8 & 32,8 & 4,6 & 1,6 \\
\hline item 5 & 2,5 & 21,3 & 26,5 & 42,3 & 5,8 & 1,6 \\
\hline item 6 & 1,0 & 7,1 & 22,9 & 54,6 & 13,1 & 1,2 \\
\hline item 7 & 1,4 & 14,8 & 37,5 & 39,1 & 5,6 & 1,6 \\
\hline item 8 & 9,2 & 48,5 & 21,5 & 16,3 & 2,9 & 1,6 \\
\hline item 9 & 1,8 & 3,9 & 15,8 & 59,5 & 17,3 & 1,6 \\
\hline item 10 & 12,0 & 64,4 & 17,8 & 3,6 & 0,8 & 1,4 \\
\hline item 11 & 16,5 & 49,8 & 27,4 & 4,4 & 0,6 & 1,4 \\
\hline
\end{tabular}

Tabel 3 Factorladingen op Factor 1

\begin{tabular}{|c|c|c|c|c|}
\hline \multirow[b]{2}{*}{ Item } & \multicolumn{2}{|c|}{ Zorgverzekeraars } & \multicolumn{2}{|c|}{ VGZ } \\
\hline & Groep 1 & Groep 2 & Groep 1 & Groep 2 \\
\hline 1 & $-0,57$ & $-0,59$ & $-0,72$ & $-0,61$ \\
\hline 2 & 0,50 & 0,41 & 0,60 & 0,66 \\
\hline 3 & $-0,57$ & $-0,55$ & $-0,58$ & $-0,51$ \\
\hline 4 & 0,46 & 0,59 & 0,59 & 0,63 \\
\hline 5 & 0,46 & 0,46 & 0,49 & 0,62 \\
\hline 6 & 0,59 & 0,53 & 0,61 & 0,60 \\
\hline 7 & 0,64 & 0,66 & 0,64 & 0,65 \\
\hline 8 & $-0,42$ & $-0,52$ & $-0,42$ & $-0,41$ \\
\hline 9 & 0,55 & 0,55 & 0,53 & 0,50 \\
\hline 10 & $-0,67$ & $-0,71$ & $-0,67$ & $-0,59$ \\
\hline 11 & $-0,74$ & $-0,76$ & $-0,78$ & $-0,72$ \\
\hline
\end{tabular}

NB. Groep 1 = exploratieve factoranalyse op de antwoorden van $75 \%$ van de respondenten; Groep $2=$ bevestigende factoranalyse op de antwoorden van $25 \%$ van de respondenten.

Tabel 4 Pearson-correlaties tussen het vertrouwen in de zorgverzekeraar, algemeen oordeel over de zorgverzekeraar en de intentie om verzekerd te blijven bij de zorgverzekeraar.

\begin{tabular}{|c|c|c|c|}
\hline & 1 & 2 & 3 \\
\hline Vertrouwen in de zorgverzekeraar (1) & 1 & & \\
\hline Tevredenheid met de zorgverzekeraar (2) & $0,51^{\star}$ & 1 & \\
\hline Intentie om verzekerd te blijven bij de zorgverzekeraar (3) & $0,50^{*}$ & $0,54^{*}$ & 1 \\
\hline
\end{tabular}

